\title{
Screening the Optimal Patterned Surfaces Consisting of Cell Morphology Mimicking Micro-pillars and Nanotube Arrays for the Design of Titanium Implants
}

\author{
Ping Zhou ${ }^{1}$, Hongjiao Li ${ }^{1}$, Feifei Mao ${ }^{2}$, Hongxin Huang ${ }^{1}$, Siqi Long ${ }^{1}$, Fei He ${ }^{1}$, Jing Chen ${ }^{3 *}$, Shicheng Wei ${ }^{2 *}$ \\ 1. School and Hospital of Stomatology, Lanzhou University, Lanzhou 730000, China \\ 2. Central Laboratory, Peking University School and Hospital of Stomatology, Beijing 100081, China \\ 3. Institute of Microelectronics, Peking University, Beijing 100871, China
}

\begin{abstract}
Micron/nano scale topographic modification has been a significant focus of interest in current titanium (Ti) surface design. However, the influence of micron/nano structured surface on cell or bacterium behavior on the Ti implant has rarely been systematically evaluated. Moreover, except for popular microgrooves, little work has been carried out on the reaction of cells to the bionic structure. In this study, several micro-pillars mimicking cell morphology were prepared on Ti surfaces by lithography and contact printing (ICP) method, and they were further decorated with nanotube arrays by anodization technology. These surface modifications remarkablly increased the surface roughness of pristine Ti surface from $91.17 \mathrm{~nm} \pm 5.57 \mathrm{~nm}$ to be more than $1000 \mathrm{~nm}$, and reduced their water contact angles from $68.3^{\circ} \pm$ $0.7^{\circ}$ to be $16.9^{\circ} \pm 2.4^{\circ}$. Then, the effects of these hierarchical micron/nano scale patterns on the behaviors of MG63 osteoblasts, L929 fibroblasts, SCC epithelial cells and $P$. gingivalis were studied, aiming to evaluate their performance in osseointegration, gingival epithelial sealing and antibacterial ability. Through an innovative scoring strategy, our findings showed that square micro-pillars with $6 \mu \mathrm{m}$ width and $2 \mu \mathrm{m}$ height combined with $85 \mathrm{~nm}$ diameter nanotubes was suitable for implant neck design, while square micro-pillars with $3 \mu \mathrm{m}$ width and $3.6 \mu \mathrm{m}$ height combined with $55 \mathrm{~nm}$ diameter nanotubes was the best for implant body design. Our study reveals the synergistic effect of the hierarchical micron/nano scale patterns on MG63 osteoblasts, L929 fibroblasts, SCC epithelial cells and $P$. gingivalis functions. It provides insight into the design of biomedical implant surfaces.
\end{abstract}

Keywords: hierarchical micron/nano design, cell-like patterns, nanotube arrays, titanium implants, implant osseointegration Copyright $(\odot)$ The author(s) 2021.

\section{Introduction}

Titanium (Ti) dental implants have been widely used for the replacement of missing teeth because of their predictable performance in the clinic. Ideally, epithelial cells and fibroblasts adhere to the implant neck surface to form a barrier, while osteoblasts exhibit a direct contact with the implant surface via canaliculisecrete and secrete matrix proteins for osseointegration on the implant body surface to withstand occlusal loading ${ }^{[1,2]}$. Both soft tissue seal around implants and stable osseointegration are essential for the long-term survival of an implant. However, a considerable number of implants failure occurred mainly related to peri-implantitis, which is the consequence of bacterial plaque penetrating the peri-implant sulcus ${ }^{[3]}$. To achieve excellent performance in implant healing, strategies such as grafting chemical compounds, self-assembly of monolayers, compaction of nanoparticles, ion beam deposition, acid etching, peroxidation, sol-gel deposition and discrete crystalline deposition have been established for the surface modification of dental implants ${ }^{[4-6]}$. Unfortunately, most of these methods exhibit shortcomings including promoting bacteria adhesion, coating material shedding from the substrate, non-uniformity in deposited layer thickness, cytotoxicity, and so on ${ }^{[5]}$. Moreover, all of them do not systematically consider the performance of dental implants in osseointegration, epithelial bonding, and antibacterial properties. Therefore, to design the ideal implant neck and body surface, novel surface modification methods are still needed.

With the quick development of microfabrication technology, a large number of graded surface morphology and ordered pattern surfaces have been developed ${ }^{[7,8]}$.

\footnotetext{
*Corresponding author: Shicheng Wei, Jing Chen

E-mail: sc-wei@pku.edu.cn, j.chen@pku.edu.cn
} 
They inherit and integrate unique natural biological surface characteristics. As early as in 1964, Curtis et al. reported that cells react to the topography of subsrates ${ }^{[9]}$. Since then, numerous studies have reported the effect of surface topography at micon scale on the behavior of cells inculding morphology, adhesion, proliferation, alignment, gene expression and differentiation ${ }^{[9-11]}$. For the nanotopography, down-regulations were found for focal adhesion formation, cell attachment, cell proliferation and cell spreading ${ }^{[12-14]}$. But, nanostructures have confirmed their ability to promote the differentiation of cells $^{[14,15]}$. Besides, customized nanotopography were popularly applied to promote osseointegration and reduce bacterial adhesion ${ }^{[16-20]}$. Unfortunately, it is reported that micron-scale topography not only could improve the osteoblastic activity and osseointegration but also increased bacterial accumulation, which increases the chance of implant infection ${ }^{[1]}$. For a nanostructured surface, better bone healing with reduced bacterial adhesion realized by specific protein interactions ${ }^{[1,21]}$. Among the various nanostructures, $\mathrm{TiO}_{2}$ nanotubes with a simple fabrication process and controllable size have attracted much attention. However, nanoscale topography is insufficient to get robust osseointegration lonely, which may because a micron-scale structure is of additional effect to the osseointegration process ${ }^{[22]}$. Thus, it has a great value to prepare hybrid hierarchical micron/nano scale structures on dental implant surfaces.

Benefit from the continuous development of microfabrication, deep reactive ion etching technology of Inductively Coupled Plasma (ICP) can easily prepare designed micron-scale patterns on the Ti substrate surfaces. Moreover, anodization technology has been widely applied to fabricate $\mathrm{TiO}_{2}$ nanotubes on Ti surfaces to regulate cell behavior by changing nanotubes diameter and cell types. Recently, we researched the effects of various hierarchical micron/nano scale patterns on the growth of implant-healing related cells and bacteria systematically ${ }^{[23]}$. However, only simple microgroove patterns with different widths and depths were studied. It is reported that ordered patterns exhibit complex effects on the adhesion and proliferation of cells, and their responses depend on cell types, feature sizes, shapes, as well as physical and chemical properties of the substrate material ${ }^{[24]}$. Therefore, it is significant to further design hybrid hierarchical micron/nano scale patterns with particular morphology on the implant surface, and search the appropriate pattern model.

In this study, rhombus or square micro-pillars resemble cell morphology were prepared on the Ti implant surfaces by ICP etching method, and nanotube arrays were further decorated by anodization technology. Then, the growth of osteoblasts, fibroblasts, epithelial cells and $P$. gingivalis on these hierarchical micron/nano scale substrates were systematically investigated to evaluate their abilities in osseointegration, gingival epithelial sealing and bacterial resistance. Finally, using an innovative scoring strategy, we find the ideal design for the neck and body surface of $\mathrm{Ti}$ implants, respectively. Our study will provid far-reaching insights for later studies, and contribut a new strategy for the modification of patterned surface on the neck and body implants.

\section{Materials and methods}

\subsection{Fabrication of hierarchical micron/nano scale patterns mimicking cell morphology on Ti sur- faces}

The titanium (Ti) specimens with a diameter of 4 inches were mechanically polished using $\mathrm{SiC}$ sandpapers and followed by several cleaning processes using concentrated sulfuric acid, 5\% dilute hydrochloric acid and ultrasonic cleaning machine as we recently reported $^{[23]}$. Micron-scale patterns resemble cell morphology with a height of $2 \mu \mathrm{m}$, or $3.6 \mu \mathrm{m}$ were prepared on the Ti surfaces through the photolithography and ICP etching technology. In this study, four kinds of patterns were designed as follows: (1) rhombus with $60^{\circ}$ acute angle, $6 \mu \mathrm{m}$ width and $30 \mu \mathrm{m}$ length (Cell 1); (2) rhombus with $60^{\circ}$ acute angle, $3 \mu \mathrm{m}$ width and $15 \mu \mathrm{m}$ length (Cell 2); (3) square with $3 \mu \mathrm{m}$ width and $20 \mu \mathrm{m}$ length (Cell 3); (4) square with $6 \mu \mathrm{m}$ width and $40 \mu \mathrm{m}$ length (Cell 4). Moreover, these Ti discs were further decorated by nanotubes with a diameter of $85 \mathrm{~nm}$ or $55 \mathrm{~nm}$ using anodization technology. These preparation processes were the same as we recently described ${ }^{[23]}$. Finally, the Ti discs were cut into square discs with $3 \mathrm{~mm}$ diameter using a laser. Besides, surface characterization was performed for these Ti samples as described in the supplementary file. 


\subsection{Cell viability assay}

Human osteoblast-like MG63 cells (MG63 for short), mouse L929 fibroblast cells (L929 for short), and human oral Squamous Cell Carcinoma-derived epithelial cell line (SCC for short) were maintained under standard conditions as mentioned previously ${ }^{[23]}$. After sterilizing by UV irradiation, Ti discs were placed into each well of 96-well cell culture plates. After cell counting, MG63, L929 and SCC were seeded into each wells at a density of $2 \times 10^{4}$ cells $\cdot \mathrm{cm}^{-2}$ respectively. After culturing for $4 \mathrm{~h}$ or $72 \mathrm{~h}$, the number of MG63, L929 and SCC on the Ti surfaces was evaluated using a cell counting kit-8 (CCK-8) assay as recently described $^{[23]}$.

\subsection{Bacterial attachment assay}

P. gingivalis (ATCC33277) was cultured in Brain Heart Infusion (BHI) medium that supplemented with $10 \mathrm{~g} \cdot \mathrm{L}^{-1}$ proteose peptone, $2 \mathrm{~g} \cdot \mathrm{L}^{-1}$ dextrose, $5 \mathrm{~g} \cdot \mathrm{L}^{-1}$ sodium chloride and $2.5 \mathrm{~g} \cdot \mathrm{L}^{-1}$ disodium phosphate under anaerobically condition. The bacterial attachment assay was conducted as we previously reported ${ }^{[23]}$. Briefly, $10 \mu \mathrm{L}$ bacterial suspension and $190 \mu \mathrm{L}$ BHI medium were incubated with sterilized Ti discs, and the viability of bacteria after $6 \mathrm{~h}$ in incubation on the Ti discs was measured using a microplate reader at $450 \mathrm{~nm}$ wavelength. All applied reagents for cell and bacterial experiment were listed in the supplementary file.

\subsection{Scoring criteria for the viability of cell and bac- terial on the Ti surfaces}

In order to systematically evaluate the influence of micron/nano topologies with different parameters on the activity of related cells and bacteria on the implant surface, we set a novel scoring criteria based on the statistical analysis as described in the supplementary file. The scores according to the following rules: (1) more L929 and SCC cells on the neck surface are recorded as positive values but not for the body surface; (2) the growth of MG63 only be calculated on the body surface; (3) the inhibition of $\mathrm{Pg}$ is recorded as positive values in both the neck and body; (4) The difference between the experimental group and the control group is within $10 \%, 10 \%$ $-30 \%, 30 \%-50 \%, 50 \%$ or more, recorded as $0,1,2,3$ respectively.

\section{Results and discussion}

\subsection{Preparation and surface characterization of hierarchical micron/nano scale cell-like patterns on Ti substrates}

To achieve excellent dental implantation in clinical, it is essential to explore suitable Ti surface harbor good performances in epithelium junction, antibacterial and osseointegration. As shown in Fig. 1, micro-pillar patterns mimicking cell morphology and $\mathrm{TiO}_{2}$ nanotubes with changing parameter settings were prepared on the Ti implant surfaces using ICP etching and anodization technology respectively as we recently described ${ }^{[23]}$. Then, SEM and AFM analyses demonstrated that 4 kinds of micro-pillar patterns mimicking cell morphology were successfully manipulated on the Ti surfaces (Fig. 1, Fig. S1). Besides, nanotube arrays with a diameter of $55 \mathrm{~nm}$ or $85 \mathrm{~nm}$ were prepared together with recently published microgroove patterned Ti substrates, which has been confirmed by SEM images ${ }^{[23]}$.

The parameters for cell-like micro-pillars were designed according to reported references ${ }^{[24-27]}$. First, the morphology of mammalian cells is mostly polygonal or fusiform. Considering microgroove pattern has been popularly prepared for fibroblast-like cells with elongated and spindle shape, it is of significance to design microstructure patterns mimicking the polygonal or fusiform shape on the Ti implant surface. Besides, it is easier to prepare micro-pillars with designed morphology on the Ti substrate surfaces than micro-hollow. Second, Green et al. found that fibroblasts on the $2 \mu \mathrm{m}$ and $5 \mu \mathrm{m}$ square micro-pillars arrays showed increased rates of proliferation and cell density as compared with their down counterparts ${ }^{[24]}$. Third, the widths and length of micro-pillars were designed according to the dimension of live cells ranged from $5 \mu \mathrm{m}$ to $100 \mu \mathrm{m}$, and sizes of $2 \mu \mathrm{m}, 5 \mu \mathrm{m}, 7 \mu \mathrm{m}, 10 \mu \mathrm{m}, 25 \mu \mathrm{m}$ or $50 \mu \mathrm{m}$ have been reported to investigate the effect of micro-pillars surface modification on cell behavior ${ }^{[24-27]}$. Take our manufacturing process into consideration, rhombus patterns of $6 \mu \mathrm{m}$ width and $30 \mu \mathrm{m}$ length, rhombus patterns of $3 \mu \mathrm{m}$ width and $30 \mu \mathrm{m}$ length, squares patterns of $3 \mu \mathrm{m}$ width and $20 \mu \mathrm{m}$ length, square patterns of $6 \mu \mathrm{m}$ width and $40 \mu \mathrm{m}$ length were prepared respectively. Values of $2 \mu \mathrm{m}$ and $3.6 \mu \mathrm{m}$ were applied to be the height of 


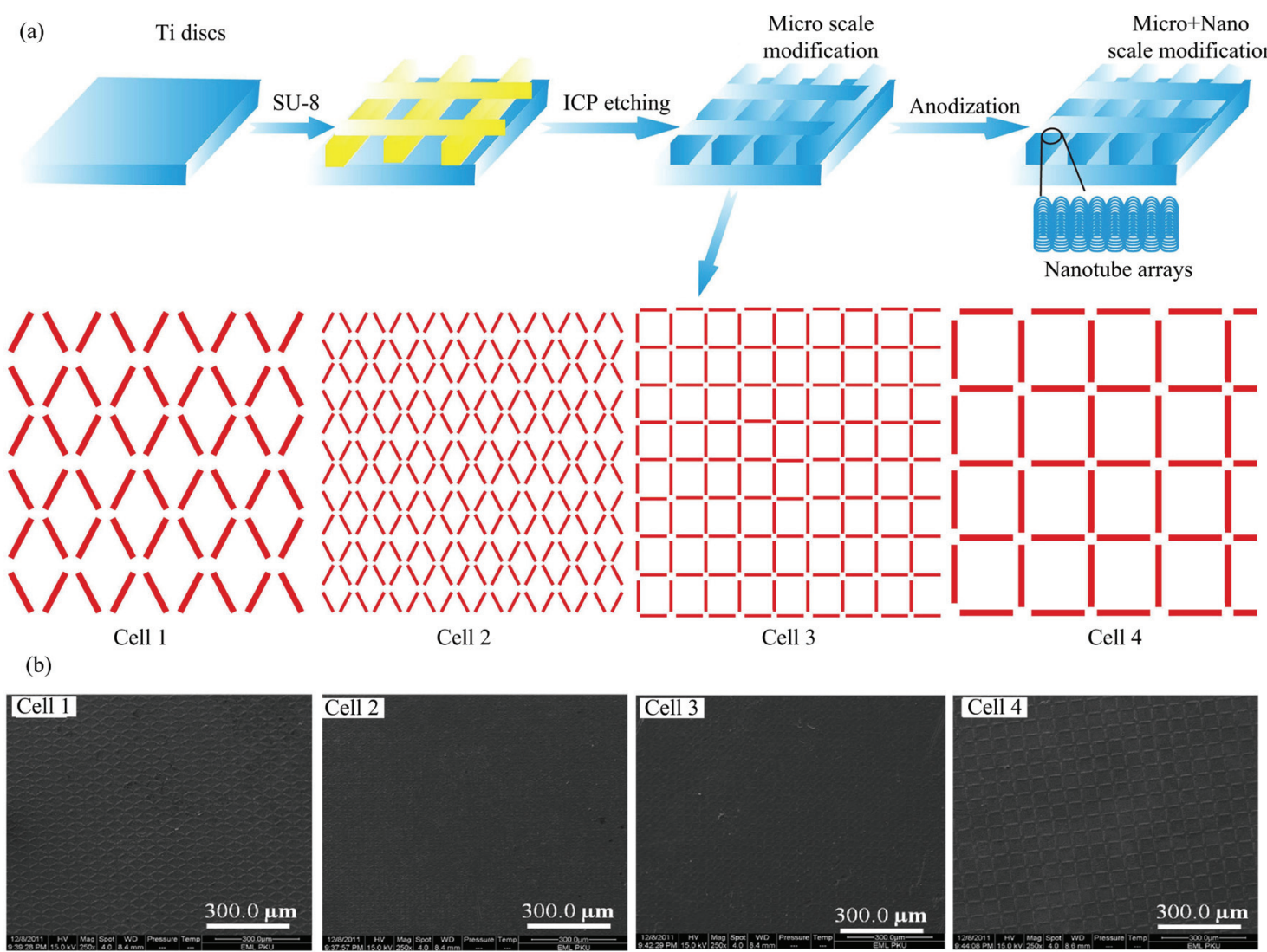

Fig. 1 (a) Preparation process of micron-scale patterns and nanotubes on titanium (Ti) discs, (b) micro-pillars with indicated topography on Ti discs. Moreover, the surface morphology of these micron-scale patterned Ti surfaces were detected by SEM.

micro-pillars in our study.

It is reported that rough surface could improve the adhesion and differentiation of osteoblasts, but a contrast effect was found for fibroblasts ${ }^{[28,29]}$. In this study, the surface roughness of Ti samples was measured by AFM (Fig. S1). The $R a$ value of Ti surfaces was significantly increased after the modification of micro-pillars (Fig. 2a), which is consistent with previous studies showing that microstructures could increase the surface roughness ${ }^{[23,30]}$. The $R a$ value of rhombus morphology micro-pillars (Cell 1) was much less than square morphology (Cell 4) when the pillar width was $6 \mu \mathrm{m}$. Although much rougher surfaces were detected for both rhombus and square morphology patterns after changing the pillar width from $6 \mu \mathrm{m}$ into $3 \mu \mathrm{m}$, the $R a$ value of rhombus morphology pillar (Cell 2) was higher than square morphology (Cell 3). It may be due to the instrument limitations of AFM analysis with a scanning area of $24 \mu \mathrm{m} \times 24 \mu \mathrm{m}$. Consistently, the $R a$ value of Ti surfaces was remarkably augmented after the decoration of $85 \mathrm{~nm}$ diameter nanotube arrays (Fig. 2b, Fig. S2a) ${ }^{[23]}$. Interestingly, Cell 1 surface exhibited higher $R a$ value than Cell 4 surface when further modified with both $85 \mathrm{~nm}$ and $55 \mathrm{~nm}$ diameter nanotube arrays (Figs. $2 \mathrm{~b}$ and 2c, Fig. S2a). Decreasing the diameter of nanotubes from $85 \mathrm{~nm}$ into $55 \mathrm{~nm}$, higher surface roughness results were found for $6 \mu \mathrm{m}$ width surfaces, but lower surface roughness results were found for $3 \mu \mathrm{m}$ width samples (Figs. $2 b$ and 2c, Fig. S2a). This is consistent with the fact that the $R a$ values of $85 \mathrm{~nm}$ diameter nanotubes on the Ti surface were much higher than $55 \mathrm{~nm}$ diameter nanotubes, as we recently reported ${ }^{[8]}$. Finally, increasing the pillar height from $2 \mu \mathrm{m}$ to $3.6 \mu \mathrm{m}$, the $R a$ values of surfaces with $55 \mathrm{~nm}$ diameter nanotube arrays and $6 \mu \mathrm{m}$ width rhombus (Cell 1) or $3 \mu \mathrm{m}$ width square (Cell 3) morphology micro-pillars were remarkably decreased, but positive effects were found for other two types Cell surfaces (Figs. 2c and 2d, Fig. S2a). In theory, higher micro-pillars contribute to more rough surface. We speculated that the height of micro-pillars on the $\mathrm{Ti}$ 

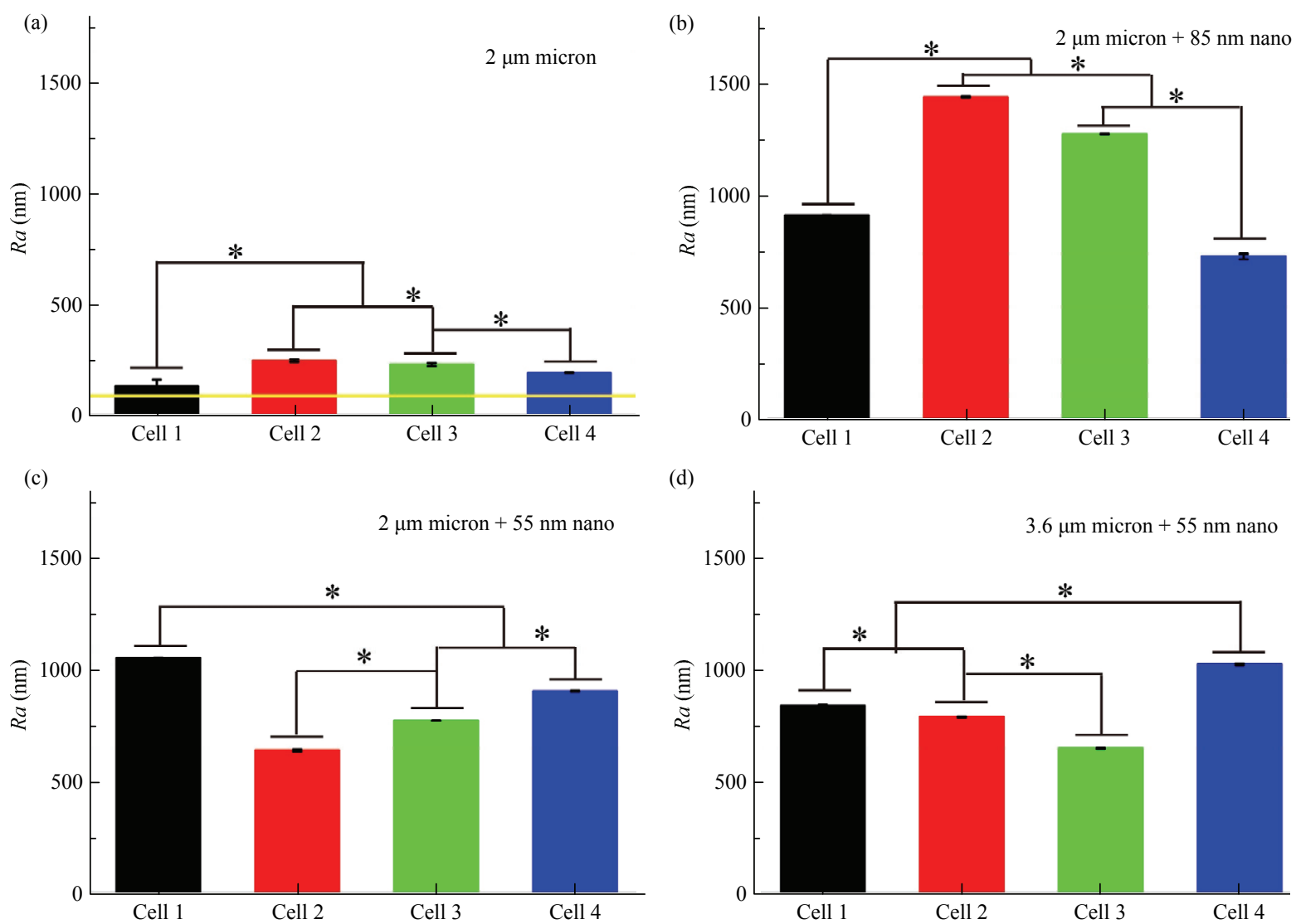

Fig. 2 Surface roughness measurements for Ti substrate surfaces by AFM. (a) $2 \mu \mathrm{m}$; (b) $2 \mu \mathrm{m}+85 \mathrm{~nm}$; (c) $2 \mu \mathrm{m}+55 \mathrm{~nm}$; (d) $3.6 \mu \mathrm{m}+$ $55 \mathrm{~nm}$. Yellow line indicates the surface roughness of the pristine Ti surface. * represents $p<0.05, n=9$.

substrate surfaces may affect the subsequent formation of nanotubes.

It is well known that hydrophilicity is a crucial factor in evaluating the surface performance of implants, and hydrophilic surface is benefit to cell adhesion and osseointegration $^{[31]}$. Hence, the water contact angle of Ti samples that decorated by micro-pillars and nanotubes was characterized using a statical goniometer (Fig. 3). The water contact angles of Ti surfaces were significantly increased after the modification of micro-pillars. Both for $6 \mu \mathrm{m}$ and $3 \mu \mathrm{m}$ width settings, rhombus micro-pillars showed higher water contact angles than square, and square micro-pillars with $3 \mu \mathrm{m}$ width (Cell 3) showed the best hydrophilicity (Fig. 3a, Fig. S2b). However, these results were completely reversed after the modification of nanotubes, and surfaces with Cell 3 and $85 \mathrm{~nm}$ or $55 \mathrm{~nm}$ diameter nanotubes showed the highest water contact angle (Figs. $3 \mathrm{~b}$ and 3c, Fig. S2b). This may be since the arrangement of nanotubes was consistent with rhombus micro-pillars but intersects with square micro-pillars. These results are consistent with the reported opinion that the hydrophilicity of the micron patterned surfaces was enhanced when the surface area increased ${ }^{[32]}$. Then, the contact angles of these $\mathrm{Ti}$ surfaces with hierarchical micron/nano scale patterns were all increased when the diameter of the nanotubes changed from $85 \mathrm{~nm}$ to $55 \mathrm{~nm}$, which is consistent with our previous study that nanotubes with diameter of $55 \mathrm{~nm}$ on Ti surfaces exhibit much higher water contact angles than $85 \mathrm{~nm}$ diameter nanotubes (Figs. 3b and 3c, Fig. S2b) ${ }^{[23]}$. Interestingly, the contact angles of all these samples were significantly reduced when the height of micron structures increased into $3.6 \mu \mathrm{m}$. These results proved that modification of micro-pillars with $3.6 \mu \mathrm{m}$ height and nanotubes with a diameter of $55 \mathrm{~nm}$ could increase the hydrophilicity of Ti substrates surface, but the hydrophobicity of Ti samples was increased when the height of the micro-pillars was $2 \mu \mathrm{m}$ and the diameter of the nanotube was $85 \mathrm{~nm}$ (Figs. $3 \mathrm{~b}$ and 3d). 

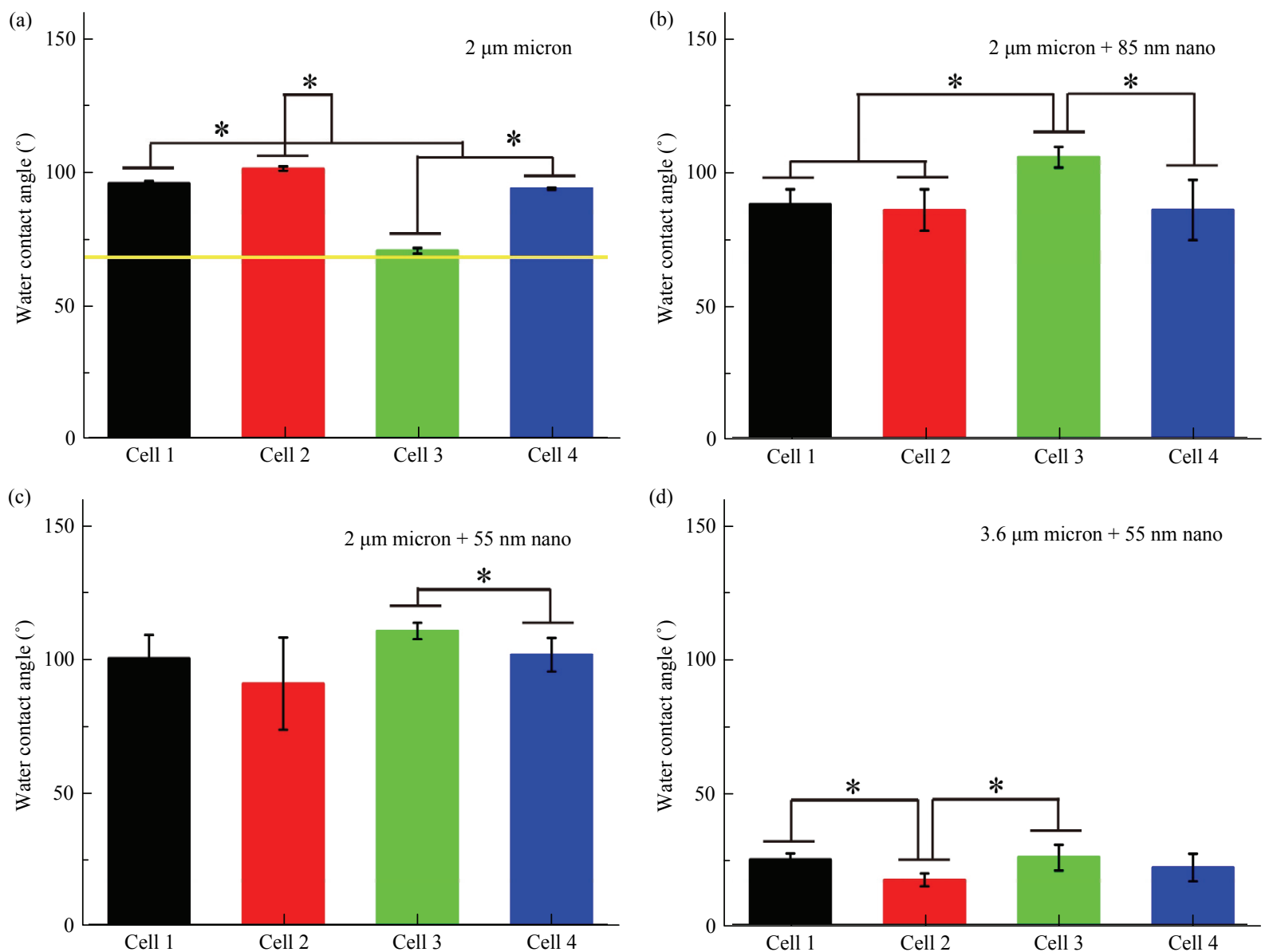

Fig. 3 Water contact angles of Ti substrate surfaces. (a) $2 \mu \mathrm{m}$; (b) $2 \mu \mathrm{m}+85 \mathrm{~nm}$; (c) $2 \mu \mathrm{m}+55 \mathrm{~nm}$; (d) $3.6 \mu \mathrm{m}+55 \mathrm{~nm}$. Yellow line indicates the water contact angles of the pristine Ti surface. * represents $p<0.05, n=8$.

\subsection{The adhesion and proliferation of cells on $\mathrm{Ti}$ substrates}

MG63 osteoblasts, L929 fibroblasts, and SCC epidermal cells that participate in implant integration were cultured on Ti surfaces with various micron/nano scale patterns for $4 \mathrm{~h}$ and $72 \mathrm{~h}$. For both time points, no statistical difference was detected in cell number of MG63 cells on Ti surfaces after decorated by cell mimicking micro-pillars with $2 \mu \mathrm{m}$ height (Fig. S3a). This proved that micron-scale cell morphology patterns have little effect on the adhesion and proliferation of MG63 cells. However, the results of better adhesion at $4 \mathrm{~h}$ and more cell number at $72 \mathrm{~h}$ were found after further modified with $85 \mathrm{~nm}$ diameter nanotubes (Fig. S3b). The reason may be that the surface roughness and surface area increased after the addition of the nanotubes, and a large number of prominent filopodia, unidirectional lamelli- podia extensions apparently on the structure of the nanotube. Changing the nanotubes diameter from $85 \mathrm{~nm}$ to $55 \mathrm{~nm}$, the cell number of MG63 cells after $4 \mathrm{~h}$ of culture on hierarchical micron/nano scale patterns were decreased, but slightly higher cell number was measured after incubation for $72 \mathrm{~h}$ for all four types micro-pillars, which may be due to that as the diameter of the nanotube changed from $85 \mathrm{~nm}$ to $55 \mathrm{~nm}$, reduced roughness in rhombus or square micro-pillars with $3 \mu \mathrm{m}$ width is not conducive to MG63 cells adhesion, but the decreased surface hydrophilicity is conducive to MG63 cells proliferation (Figs. $4 \mathrm{a}$ and $4 \mathrm{~b}$, Figs. S3b and S3c). Rougher surface are more tend to exhibit attributes of osteoblasts than cells cultured on smoother surfaces, which were previously stated by Ortega et al ${ }^{[11]}$. Finally, the adhesion of cells on hierarchical $55 \mathrm{~nm}$ diameter nanotubes and rhombus micro-pillars were remarkably 
(a)

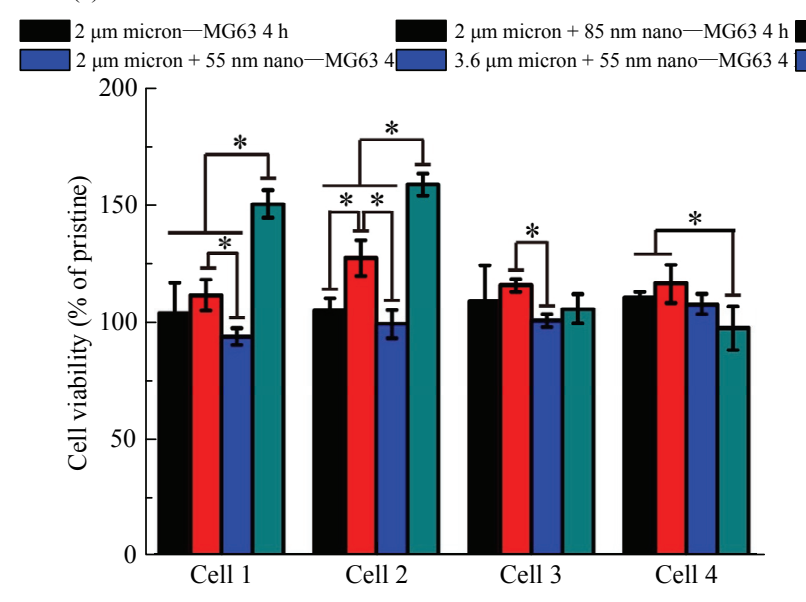

(b)

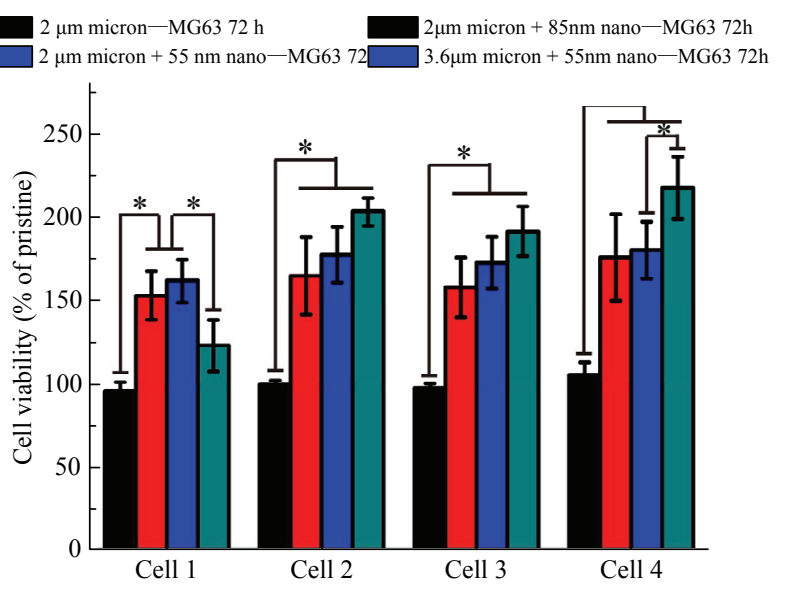

(d)

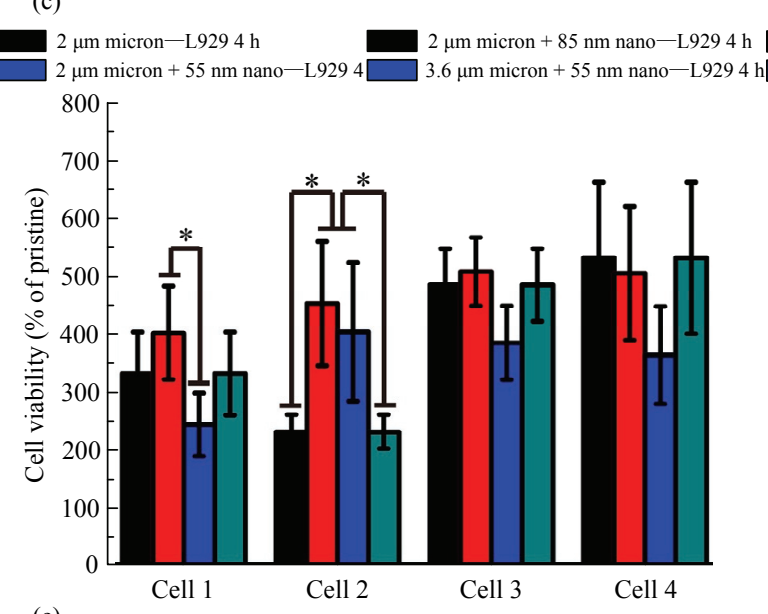

(e)

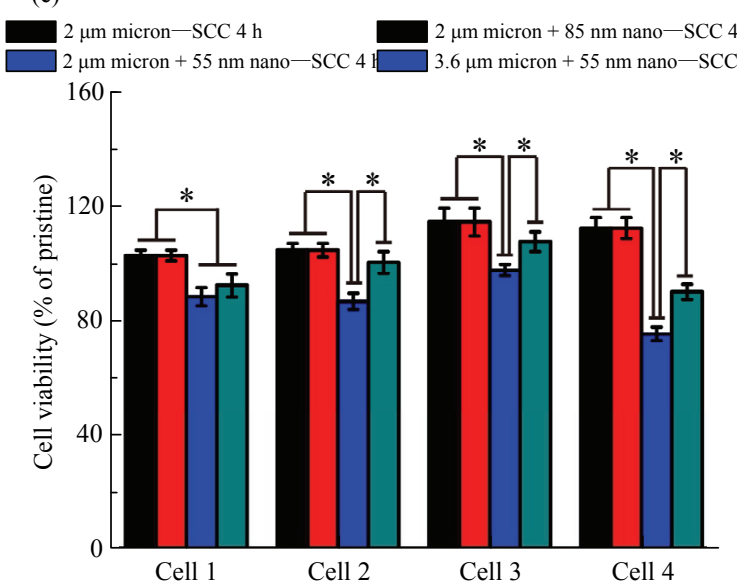

(f)
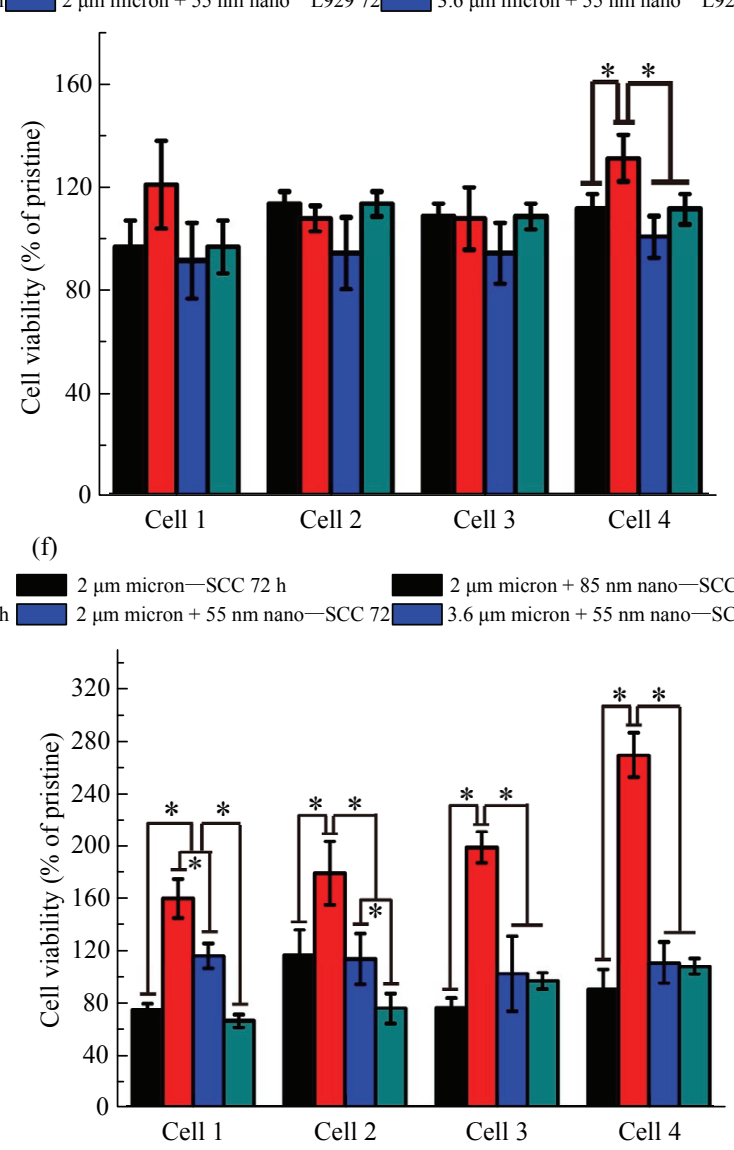

Fig. 4 Cell number measurements on the modified Ti surfaces. (a-f) The number of MG63 cells, L929 cells and SCC cells after culturing on the Ti surfaces that decorated by indicated micro-pillars and nanotubes for $4 \mathrm{~h}(\mathrm{a}, \mathrm{c}, \mathrm{e})$ or $72 \mathrm{~h}(\mathrm{~b}, \mathrm{~d}, \mathrm{f})$ respectively.

accelerated when the pillar height changed from $2 \mu \mathrm{m}$ to $3.6 \mu \mathrm{m}$, but not for square micro-pillars (Figs. $4 \mathrm{a}$ and $4 \mathrm{~b}$, Fig. S3d). Went on cultured for $72 \mathrm{~h}$, MG63 cells on square micro-pillar groups showed comparable cell number to $3 \mu \mathrm{m}$ width rhombus patterns. Notably, sur- face with $6 \mu \mathrm{m}$ width and $30 \mu \mathrm{m}$ length rhombus micro-pillars and $55 \mathrm{~nm}$ diameter nanotubes went against the proliferation of MG63 cells as confirmed by the low cell number result at $72 \mathrm{~h}$.

For L929 fibroblasts with culturing time of $4 \mathrm{~h}$, 
much more attached cells were found on each cell mimicking micro-pillars, and the number of cells was all increased after further decorated by nanotube arrays (Figs. 4c and 4d, Fig. S4a-S4c). Then, we discovered that surfaces with micro-pillars and $85 \mathrm{~nm}$ diameter nanotubes were more favorable to cell adhesion in comparison to surfaces decorated with a $55 \mathrm{~nm}$ diameter parameter (Fig. 4c, Figs. S4b and S4c). It may be due to the fact that $85 \mathrm{~nm}$ diameter nanotubes provide the substantially increased surface area with unique characteristics, which is more conductive to the cell adhesion ${ }^{[33]}$. Changing the height of micro-pillars to be $3.6 \mu \mathrm{m}$, the cell number of attached L929 on Ti surfaces with hierarchical patterns were increased other than Cell 2, and square morphology groups showed higher cell number than rhombus morphology groups (Fig. 4c, Figs. S4c and S4d). Notably, for these surfaces with both micro-pillars and nanotubes, small size micron patterns showed better L929 adhesion when the pillar height was $2 \mu \mathrm{m}$ (Cell $1<$ Cell 2, Cell $3>$ Cell 4), but contrary results were measured when the pillar height was $3.6 \mu \mathrm{m}$. Unfortunately, although both micro-pillars and nanotubes can significantly improve the adhesion of L929 fibroblasts, but showed no effect on the number of cells after incubation for $72 \mathrm{~h}$ on Ti surfaces (Fig. 4d). These results are in line with previous findings that after cultivated for $72 \mathrm{~h}$, the cell viability of L929 cells shows no significant difference between hierarchical micron/nano scale patterns and the pristine Ti surfaces (Fig. S4) ${ }^{[34]}$. These results suggested that both modification of micro-pillars and nanotube arrays significangly promote the attachment of L929 fibroblasts on the Ti substrates, but also remarkably inhibit the following cell proliferation process. Fibroblasts is a cell type that express vinculin at a high level, which play a key role in the formation of focal adhesion. Both microscale and nanoscale patterns are reported to enhance the expression of vinculin in attached fibroblasts on the substate surfaces. This can explain the excellent cell adhesion results for L929 fibroblasts on the $\mathrm{Ti}$ surfaces with hierarchical micron/nano scale patterns ${ }^{[35,36]}$. However, the cell attachment strength may be too good to restrict the cell migration and the interaction of cells, which are important for the cell proliferation. Moreover, the micro-pillars could also separate each of single cells, re- sulting in limited cell proliferation and cell apoptosis after $72 \mathrm{~h}$ of culture.

At last, we detected the number of human epithelial cell lines SCC on Ti surfaces that decorated by various micron/nano scale patterns (Figs. 4e and 4f). It was found that cell mimicking micro-pillars could slightly accelerate the adhesion of SCC cells, and square morphology harbor better performance in sustaining adhesion of SCC cells than rhombus (Fig. S5a). Except for Cell 2 group, much fewer cells were detected on these Ti surfaces after $72 \mathrm{~h}$ in culture. Although similar cell attachment results were found after further decorated by $85 \mathrm{~nm}$ diameter nanotubes, the cell number of SCC cells were significantly increased after incubation for $72 \mathrm{~h}$ (Fig. 4f, Fig. S5b). This proved that nanostructure with a diameter of $85 \mathrm{~nm}$ could apparently promote the proliferation of SCC cells. However, decreasing the diameter of nanotubes from $85 \mathrm{~nm}$ to $55 \mathrm{~nm}$ exhibited a significant side effect on the survival of SCC cells (Figs. 4e and 4f, Figs. S5b and S5c). Finally, using $3.6 \mu \mathrm{m}$ height micro-pillars, the adhesion of SCC cells on Ti surfaces with micro-pillars and $55 \mathrm{~nm}$ diameter $\mathrm{TiO}_{2}$ nanotubes were increased, but lower cell number was measured on rhombus morphology groups after $72 \mathrm{~h}$ of culture (Figs. 4e and 4f, Figs. S5c and S5d).

Our results showed that the shapes and sizes of micron structure, nanotubes diameter are factors that influence the behavior of cell biology. The possible reason is that these structures have an effect on the proteinfilm composition and molecule orientation adsorbed onto the implant surface by changing the roughness and hydrophilicity of the surface material ${ }^{[37]}$. As known, at the early stage of cell adhesion, surface roughness plays an important role. But surface hydrophilicity and topography affect cell proliferation and differentiation behavior in the later stage ${ }^{[32]}$. In this study, when the diameter of the nanotubes changed from $85 \mathrm{~nm}$ to $55 \mathrm{~nm}$, the cell number of three types cells were all decreased, which is in line with the previous study that nanotubes with a diameter of $80 \mathrm{~nm}$ can broadly promote osteoblast multiple behaviors after 10 days of culture ${ }^{[38]}$. On the nanotubes surface, particularly on the larger-diameter nanotubes, more filopodia and proteins aggregate, which would have effects on the way of how the cells perceive and attach the surface ${ }^{[39]}$. As the height of the mi- 
cro-pillars increased from $2 \mu \mathrm{m}$ to $3.6 \mu \mathrm{m}$, the growth of MG63 and L929 were enhanced, while SCC was inhibited. As for cell-like patterns, rhombus micro-pillars were more conducive to the adhesion of MG63, while square micro-pillars were more conducive to the adhesion of L929 and SCC. Therefore, in this research, osteoblasts, fibroblasts and epithelial cells would respond differently to various micron/nano scale patterns. Among four types micro-pillars, square micro-pillars with $6 \mu \mathrm{m}$ width and $3.6 \mu \mathrm{m}$ height combined with $55 \mathrm{~nm}$ diameter nanotubes showed better attachment for L929, square micro-pillars with $6 \mu \mathrm{m}$ width and $2 \mu \mathrm{m}$ height combined with $85 \mathrm{~nm}$ diameter nanotubes showed better attachment for SCC, rhombus micro-pillars with $6 \mu \mathrm{m}$ width and $3.6 \mu \mathrm{m}$ height combined with $55 \mathrm{~nm}$ diameter nanotubes are beneficial to the adhesion of MG63 (Figs. S3 - S5). Exactly, after decorated by $3.6 \mu \mathrm{m}$ micro-pillars and $55 \mathrm{~nm}$ diameter nanotubes, Cell 4 showed the highest $R a$, which is consistent with the previous study that osteoblast-like cells exhibited greater tendency to attach to rough titanium surfaces $^{[40]}$.

\subsection{Adhesion of $P$. gingivalis}

Bacterial adhesion and colonization are considered to play a vital role in the pathogenesis of peri-implant disease $^{[41]}$. Gram-negative anaerobic bacteria such as $P$. gingivalis, Tannerella forsythia, and Fusobacterium $s p$ are commonly detected in peri-implantitis around implants, and $P$. gingivalis is considered to be the leading cause $^{[42]}$. Surface topography has great influence on the attachment of bacteria to material surfaces. Many natural surfaces harbor hierarchical micron/nano structures presenting varying unique properties such as superhydrophobicity, self-cleaning and antibiofouling ${ }^{[43-45]}$. It is reported that some of the sub-micron or microscale features can minimize bacterial attachment and not influence the viability of adhered cells ${ }^{[46]}$. Thus, in this experiment, we discovered the adhesion of $P$. gingivalis on the Ti surfaces with micro-pillars and nanotubes (Fig. 5). Compared to pristine Ti surfaces, more $P$. gingivalis were found on Cell 2 and Cell 4 micro-pillars, but less for Cell 1 and Cell 3 (Fig. S6). It is surprised to find that the result of $P$. gingivalis adhesion has no correlation with the surface characters include pattern design, roughness and water contact angles. To our knowledge, factors guiding this attachment include electrostatic interactions, hydrophobicity, van der Waals forces, steric hindrances, hydrodynamic forces and others ${ }^{[47]}$. Previous studies reported that the existence of nanometer features could suppress biofilm formation by increasing fibronectin adsorption ${ }^{[1,6]}$. Besides, Ercan et al. also proved that nanotubes with a diameter of $80 \mathrm{~nm}$ on the Ti substrates showed good antibacterial activity ${ }^{[48]}$.

Consistently, above micro-pillars (Cell 2 and Cell 4) with much attached $P$. gingivalis even exhibited low bacteria vitality after further modification of $85 \mathrm{~nm}$ diameter nanotubes (Fig. 5). However, no significant difference was found for the Cell 1 and Cell 3 groups, their micro-pillars design was not benefit to the bacterial adhesion. Considering the number of attached bacterial on the $\mathrm{Ti}$ substrate surfaces with hierarchical micron/nano scale patterns are not quite different among all 4 groups, we speculated that modification of nanotubes arrays almost eliminates the affect from micro-pillars. With the diameter of nanotubes changed from $85 \mathrm{~nm}$ to $55 \mathrm{~nm}$, more bacterial were found on the Ti sample surfaces (Fig. 5, Figs. S6b and S6c). Finally, we found that increasing the height of micro-pillars could significantly suppress the bacterial adhesion on Ti surfaces with cell mimicking micro-pillars and $55 \mathrm{~nm}$ diameter

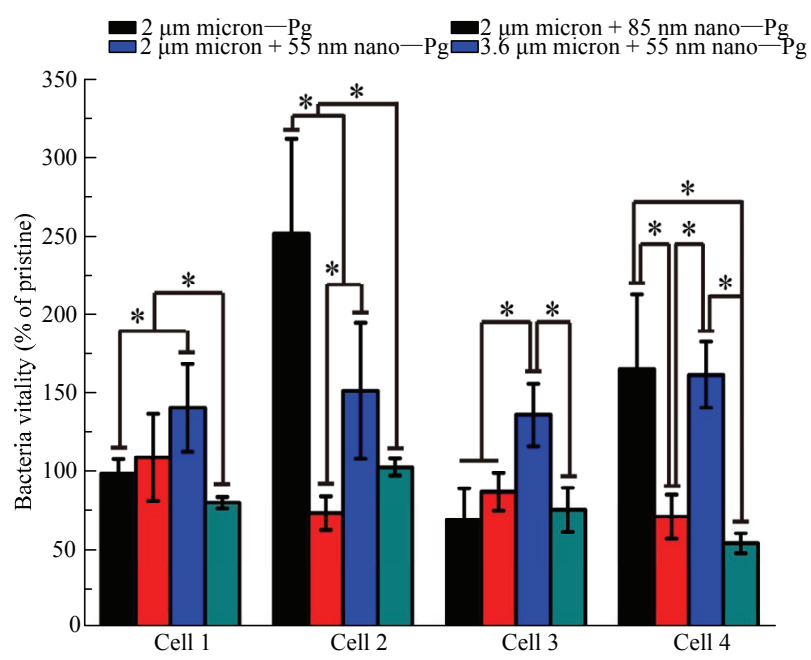

Fig. 5 Measurements of $P$. gingivalis bacteria viability on the modified Ti surfaces. The viability of $P$. gingivalis after $6 \mathrm{~h}$ of adhesion on the $\mathrm{Ti}$ surfaces that decorated by indicated micro-pillars and nanotubes. Viability is expressed as a percentage relative to the result obtained with the pristine Ti control. * represents $p<0.05$. 

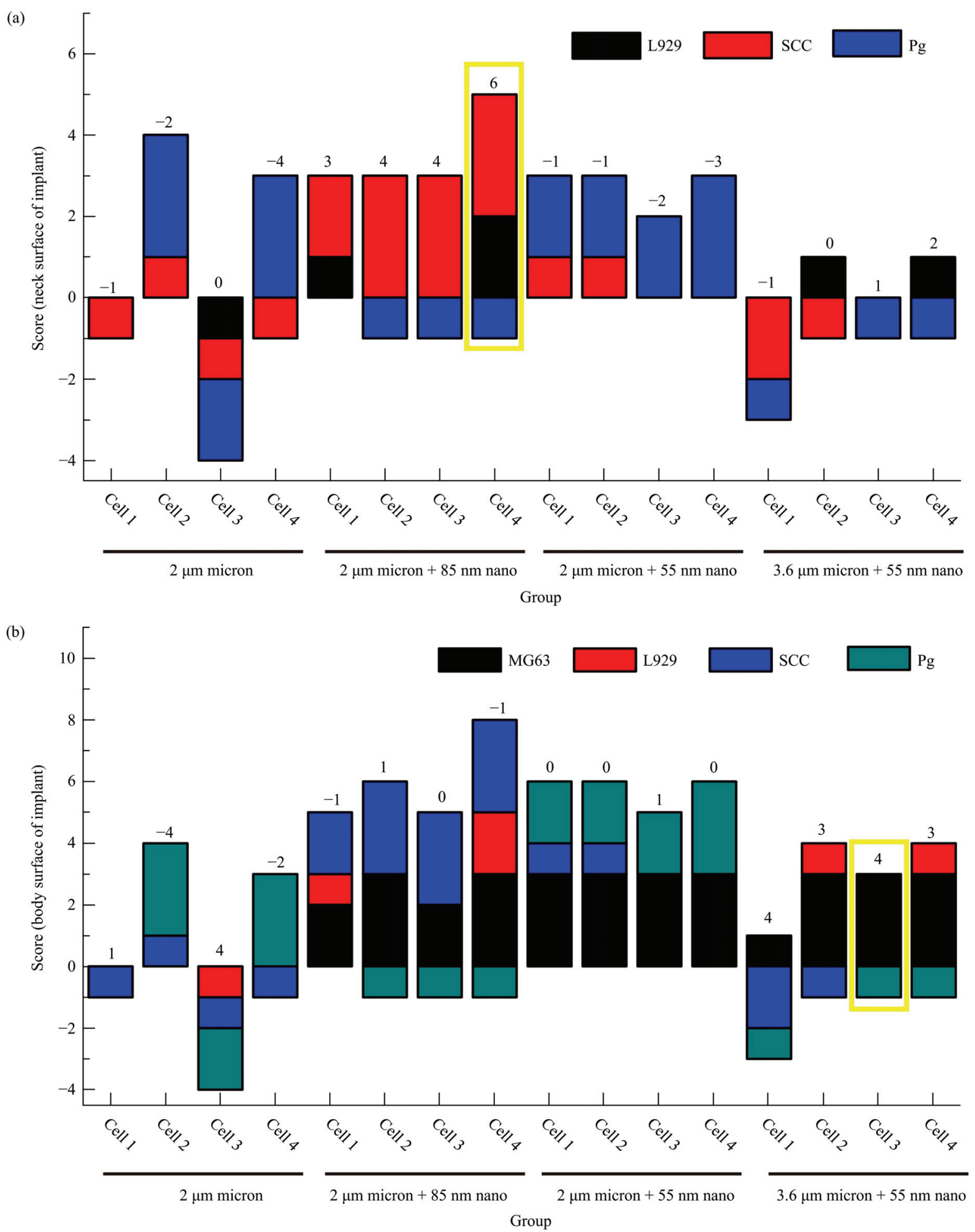

Fig. 6 Scores for the viability of osteoblast, fibroblasts, epithelial cells and $P$. gingivalis on Ti surfaces with indicated patterns. Scores for the design of implant neck surface (a) and body surface (b) respectively according to the mentioned principles.

nanotubes (Fig. 5, Figs. S6c and S6d). Among various patterns, $6 \mu \mathrm{m}$ width and $40 \mu \mathrm{m}$ length square micro-pillars with $3.6 \mu \mathrm{m}$ height and $55 \mathrm{~nm}$ diameter nanotubes showed the best antibacterial effect (Fig. 5). 


\subsection{Selecting the optimal patterned surfaces for Ti implants}

After the implant is implanted in the jaw, the implant is supposed to successfully connected to three types of cells, including epithelial cells, osteoblasts, and fibroblasts. In the body, osteoblast-derived matrix proteins and deposit bone minerals for osteogenesis and osseointegration to resist occlusal load. In the neck, epithelial cells and fibroblasts are supposed to adhere to the transmucosal component and form a barrier to protect the underlying bone tissue. Besides, both the neck and body are supposed to antibacterial. Based on these to find the ideal design for the neck and body surface of the Ti implant, respectively. Take the pristine Ti surface as a control, we scored the cell numbers and bacteria viability on above micron/nano scale patterns. Based on the scoring criteria as mentioned in the method section, we systematically analyzed the growth of related cells and bacteria during the healing of implant with these micron/nano scale patterns design, and the scores are showed in Fig. 6. On the neck of the implant, square micro-pillars with $6 \mu \mathrm{m}$ width (Cell 4) and $2 \mu \mathrm{m}$ height combined with $85 \mathrm{~nm}$ diameter nanotubes achieved the highest score of 6 , proving that this micron/nano scale pattern was suitable for the implant neck design. Exactly, micro-pillars with $2 \mu \mathrm{m}$ height and $85 \mathrm{~nm}$ diameter nanotubes showed higher cell numbers for L929 and SCC. On the body of the implant, the highest score of 4 was found on square micro-pillars with $3.6 \mu \mathrm{m}$ height and 55 $\mathrm{nm}$ diameter nanotubes, which was supposed to be the best implant body design. It is just that this surface showed better hydrophilicity, as confirmed by water contact angle measurements, which is suitable for osteointegration. The above results can guide us to design a complex Ti implant surface with excellent performance in both epithelium junction and osseointegration.

In the body scoring process, we noticed that there are three micron/nano scale patterns with a score of 4 , namely square micro-pillars with $3 \mu \mathrm{m}$ width, square micro-pillars with $3 \mu \mathrm{m}$ width, $3.6 \mu \mathrm{m}$ height and $55 \mathrm{~nm}$ diameter nanotubes, rhombus micro-pillars with $6 \mu \mathrm{m}$ width, $3.6 \mu \mathrm{m}$ height and $55 \mathrm{~nm}$ diameter nanotubes. Considering that the body of implant needs to promote bone formation, we have chosen the latter two. Besides, we found that when the height was $3.6 \mu \mathrm{m}$ and the di- ameter was $55 \mathrm{~nm}$, square micro-pillars with $3 \mu \mathrm{m}$ width were more conducive to MG63 cells than rhombus micro-pillars with $6 \mu \mathrm{m}$ width. Therefore, we believe that the best body micron/nano scale pattern was square micro-pillars with $3 \mu \mathrm{m}$ width, $3.6 \mu \mathrm{m}$ height combined with $55 \mathrm{~nm}$ diameter nanotubes. Taken together from the results of MG63, L929, SCC and P. gingivalis response to Ti substrates in this study, we found that the combination of cell-like micron patterns and nanotubes showed different effects on the cell proliferation and the activity of $P$. gingivalis. Overall, these results provide a good clue for us to design a good surface for the neck and body of the implant to expanding clinical applications.

\section{Conclusion}

In this study, using ICP etching method and anodization technology, hierarchical micron/nano scale patterns were prepared on the Ti surfaces. Results showed that among various presented patterns: (1) rhombus micro-pillars with $6 \mu \mathrm{m}$ width and $3.6 \mu \mathrm{m}$ height combined with $55 \mathrm{~nm}$ nanotubes showed better osteogenesis for MG63; (2) square micro-pillars with $6 \mu \mathrm{m}$ width and $3.6 \mu \mathrm{m}$ height combined with $55 \mathrm{~nm}$ nanotubes showed better early attachment for L929; (3) square micro-pillars with $6 \mu \mathrm{m}$ width and $2 \mu \mathrm{m}$ height combined with $85 \mathrm{~nm}$ nanotubes showed better early attachment for SCC; (4) square micro-pillars with $6 \mu \mathrm{m}$ width and $3.6 \mu \mathrm{m}$ height combined with $55 \mathrm{~nm}$ nanotubes showed the best antibacterial activity for $P$. gingivalis. Moreover, using a scoring strategy, we proved that square micro-pillars with $6 \mu \mathrm{m}$ width and $2 \mu \mathrm{m}$ height combined with $85 \mathrm{~nm}$ nanotubes was suitable for implant neck design, and square micro-pillars with $3 \mu \mathrm{m}$ width and $3.6 \mu \mathrm{m}$ height combined with $55 \mathrm{~nm}$ nanotubes was the best for implant body design. In the future, we will further study the combined effects of nanotubes and various micron structure dimensions with different topography on osseointegration and understand its mechanism of action.

\section{Acknowledgment}

This work was funded by the National Natural Science Foundation of China (No. 81801855), Young Elite Scientist Sponsorship Program by CSA (No. 
2018QNRC001), Fundamental Research Funds for the Central Universities, Chengguan District Science and Technology Project (No. 2018-7-6), Lanzhou University Hospital of Stomatology Research Support Fund.

Open Access This article is licensed under a Creative Commons Attribution 4.0 International License, which permits use, sharing, adaptation, distribution and reproduction in any medium or format, as long as you give appropriate credit to the original author(s) and the source, provide a link to the Creative Commons licence, and indicate if changes were made.

The images or other third party material in this article are included in the article's Creative Commons licence, unless indicated otherwise in a credit line to the material. If material is not included in the article's Creative Commons licence and your intended use is not permitted by statutory regulation or exceeds the permitted use, you will need to obtain permission directly from the copyright holder.

To view a copy of this licence, visit http://creativecommons.org/licenses/by/4.0/.

* All supplementary materials are available at https://doi.org/10.1007/s42235-021-0019-x.

\section{References}

[1] Miao X C, Wang D H, Xu L Y, Wang J, Zeng D L, Lin S X, Huang C, Liu X Y, Jiang X Q. The response of human osteoblasts, epithelial cells, fibroblasts, macrophages and oral bacteria to nanostructured titanium surfaces: A systematic study. International Journal Nanomedicine, 2017, 12, 1415-1430.

[2] Palmquist A. A multiscale analytical approach to evaluate osseointegration. Journal of Materials Science Materials in Medicine, 2018, 29, 60.

[3] Norowski Jr P A, Bumgardner J D. Biomaterial and antibiotic strategies for peri-implantitis: A review. Journal of Biomedical Materials Research Part B Applied Biomaterials, 2010, 88B, 530-543.

[4] Marenzi G, Impero F, Scherillo F, Sammartino J C, Squillace A, Spagnuolo G. Effect of different surface treatments on titanium dental implant micro-morphology. Materials, 2019, 12, 733-747.

[5] Jemat A, Ghazali M J, Razali M, Otsuka Y. Surface modifications and their effects on titanium dental implants, Biomed Research International, 2015, 2015, 791725.
[6] Ferraris S, Vitale A, Bertone E, Guastella S, Cassinelli C, Pan J, Spriano S. Multifunctional commercially pure titanium for the improvement of bone integration: Multiscale topography, wettability, corrosion resistance and biological functionalization. Materials Science \& Engineering C Materials for Biogical Applications, 2016, 60,384-393.

[7] Chen J, Rungsiyakull C, Li W, Chen Y H, Swain M, Li Q. Multiscale design of surface morphological gradient for osseointegration. Journal of Mechanical Behavior of Biomedical Materials, 2013, 20, 387-397.

[8] Flemming R G, Murphy C J, Abrams G A, Goodman S L, Nealey P F. Effects of synthetic micro- and nano-structured surfaces on cell behavior. Biomaterials, 1999, 20, 573-588.

[9] Curtis A S, Varde M. Control of cell behavior: Topological factors. Journal of the National Cancer Institute, 1964, 33, $15-26$.

[10] Bruinink A, Wintermantel E. Grooves affect primary bone marrow but not osteoblastic MC3T3-E1 cell cultures. Biomaterials, 2001, 22, 2465-2473.

[11] Velasco-Ortega E, Alfonso-Rodríguez C A, Monsalve-Guil L, España-López A, Jiménez-Guerra A, Garzón I, Alaminos M, Gil F G. Relevant aspects in the surface properties in titanium dental implants for the cellular viability. Materials Science and Engineering C, Materials for Biological Applications, 2016, 64, 1-10.

[12] Gallagher J O, McGhee K F, Wilkinson C D W, Riehle M O. Interaction of animal cells with ordered nanotopography. IEEE Transactions Nanobioscience, 2002, 1, 24-28.

[13] Dalby M J, Riehle M O, Sutherland D S, Agheli H, Curtis A $\mathrm{S}$ G. Changes in fibroblast morphology in response to nano-columns produced by colloidal lithography. Biomaterials, 2004, 25, 5415-5422.

[14] Andersson A S, Bäckhed F, Euler A V, Richter-Dahlfors A, Sutherland D, Kasemo B. Nanoscale features influence epithelial cell morphology and cytokine production. Biomaterials, 2003, 24, 3427-3436.

[15] Popat K C, Chatvanichkul K, Barnes G L, Latempa Jr T J, Grimes C A, Desai T A. Osteogenic differentiation of marrow stromal cells cultured on nanoporous alumina surfaces. Journal of Biomedical Materials Research Part A, 2007, 80, 955-964.

[16] Bierbaum S, Mulansky S, Bognár E, Kientzl I, Nagy P, Vrana N E, Weszl M, Boschke E, Scharnweber D, Wolf-Brandstetter C. Osteogenic nanostructured titanium surfaces with antibacterial properties under conditions that mimic the dynamic situation in the oral cavity. Biomaterials Science, 2018, 6, 1390-1402. 
[17] Abhijith N V, Priyanka C P, Sudeep U, Ramachandran K K. Crystallinity and wettability induced osteogenic behaviors of commercially pure $\mathrm{Ti}$ and $\mathrm{Ti}-6 \mathrm{Al}-4 \mathrm{~V}$ alloy implant surfaces having multiscale surface topography. Materials Today: Proceedings, 2020, in press.

[18] Jemat A, Ghazali M J, Razali M, Otsuka Y. Surface modifications and their effects on titanium dental implants. BioMed Research International, 2015, 2015, 1-11.

[19] Ferreira S P B, Gomes M C C, Claudino M, Carvalho V F, Rocha F S, Zanetta-Barbosa D. Influence of implant surfaces on osseointegration: A histomorphometric and implant stability study in rabbits. Brazilian Dental Journal, 2015, 26, 451-457.

[20] Brnemark R, Emanuelsson L, Palmquist A, Thomsen P. Bone response to laser-induced micro- and nano-size titanium surface features. Nanomedicine-Nanotechnology, Biology, and Medicine, 2010, 7, 220-227.

[21] Puckett S D, Taylor E, Raimondo T, Webster T J. The relationship between the nanostructure of titanium surfaces and bacterial attachment. Biomaterials, 2010, 31, 706-713.

[22] Mendonça G, Mendonça D B S, Aragão F J L, Cooper L F. Advancing dental implant surface technology - from micron- to nanotopography. Biomaterials, 2008, 29, $3822-3835$

[23] Zhou P, Mao F F, He F, Han Y, Li H J, Chen J, Wei S C. Screening the optimal hierarchical micro/nano pattern design for the neck and body surface of titanium implants. Colloid and Surface B - Biointerfaces, 2019, 178, 515-524.

[24] Green A M, Jansen J A, Jp V D W, von Recum A F. Fibroblast response to microtextured silicone surfaces: Texture orientation into or out of the surface. Journal of Biomedical Materials Research, 2010, 28, 647-653.

[25] Hunt J A, Williams R L, Tavakoli S M, Riches S T. Laser surface modification of polymers to improve biocompatibility. Journal of Materials Science Materials in Medicine, 1995, 6, 813-817.

[26] Staehlke S, Koertge A, Nebe B. Intracellular calcium dynamics dependent on defined microtopographical features of titanium. Biomaterials, 2015, 46, 48-57.

[27] Zhou P, Long S Q, Mao F F, Huang H X, Li H J, He F, Zhang R, Ren L L, Chen J, Wei S C. Controlling cell viability and bacterial attachment through fabricating extracellular matrix-like micron/nanostructured surface on titanium implant. Biomedical Materials, 2020, 15, 035002.

[28] Sykaras N, Iacopino A M, Marker V N, Triplett R G, Woody R D. Implant materials, designs, and surface topographies: Their effect on osseointegration. A literature review. International Journal of Oral Maxillofacial Implants, 2000, 15, 675-690.

[29] Albrektsson T, Wennerberg A. Oral implant surfaces: Part 1--review focusing on topographic and chemical properties of different surfaces and in vivo responses to them. International Journal of Prosthodontics, 2004, 17, 536-543.

[30] Brunette D M, Chehroudi B. The effects of the surface topography of micromachined titanium substrata on cell behavior in vitro and in vivo. Journal of Biomechanical Engineering - Transactions of the Asme, 1999, 121, 49-57.

[31] Bumgardner J D, Wiser R, Elder S H, Jouett R, Yang Y, Ong $\mathrm{J}$ L. Contact angle, protein adsorption and osteoblast precursor cell attachment to chitosan coatings bonded to titanium. Journal of Biomaterials Science Polymer Edition, 2003, 14, 1401-1409.

[32] Huang J Y, Zhang X C, Yan W X, Chen Z P, Shuai X T, Wang A X, Wang Y. Nanotubular topography enhances the bioactivity of titanium implants. Nanomedicine-Nanotechnology Biology and Medicine, 2017, 13, 1913-1923.

[33] Guo L T, Chen X Y, Liu X M, Feng W, Li B, Lin C, Tao X Y, Qiang Y H. Surface modifications and nano-composite coatings to improve the bonding strength of titanium-porcelain. Materials Science \& Engineering $\mathrm{C}-\mathrm{Ma}$ terials for Biogical Applications, 2016, 61, 143-148.

[34] Anselme K, Davidson P, Popa A M, Giazzon M, Liley M, Ploux L. The interaction of cells and bacteria with surfaces structured at the nanometre scale. Acta Biomaterialia, 2010, 6, 3824-3846.

[35] Miao X C, Wang D H, Xu L Y, Wang J, Zeng D L, Lin S X, Huang C, Liu X Y, Jiang X Q. The response of human osteoblasts, epithelial cells, fibroblasts, macrophages and oral bacteria to nanostructured titanium surfaces: A systematic study. International Journal of Nanomedicine, 2017, 12, 1415-1430.

[36] Pendegrass C J, Middleton C L, Gordon D, Jacob J, Blunn G W. Measuring the strength of dermal fibroblast attachment to functionalized titanium alloys in vitro. Journal of Biomedical Materials Research Part A, 2010, 92, 1028-1037.

[37] Rompen E, Domken O, Degidi M, Farias Pontes A E, Piattelli A. The effect of material characteristics, of surface topography and of implant components and connections on soft tissue integration: A literature review. Clinical Oral Implants Research, 2010, 17, 55-67.

[38] Zhao L Z, Mei S L, Chu P K, Zhang Y M, Wu Z F. The influence of hierarchical hybrid micro/nano-textured titanium surface with titania nanotubes on osteoblast functions. 
Biomaterials, 2010, 31, 5072-5082.

[39] Seunghan O, Brammer K S, Li Y S J, Teng D Y, Engler A J, Shu C, Sungho J. Stem cell fate dictated solely by altered nanotube dimension. Proceedings of the National Academy of Sciences of the United States of America, 2009, 106, 2130-2135.

[40] Martin J Y, Schwartz Z, Hummert T W, Schraub D M, Simpson J, Lankford Jr J, Dean D D, Cochran D L, Boyan B D. Effect of titanium surface roughness on proliferation, differentiation, and protein synthesis of human osteoblast-like cells (MG63). Journal of Biomedical Materials Research, 1995, 29, 389-401.

[41] Quirynen M, Soete M D, Steenberghe D V. Infectious risks for oral implants: A review of the literature. Clinical Oral Implants Research, 2010, 13, 1-19.

[42] Heitzmayfield L J, Lang N P. Comparative biology of chronic and aggressive periodontitis vs. peri-implantitis. Periodontology, 2010, 53, 167-181.

[43] Ferrari M, Benedetti A. Superhydrophobic surfaces for applications in seawater. Advances in Colloid and Interface
Science, 2015, 222, 291-304.

[44] Bixler G D, Theiss A, Bhushan B, Lee S C. Anti-fouling properties of microstructured surfaces bio-inspired by rice leaves and butterfly wings. Journal of Colloid and Interface Science, 2014, 419, 114-133.

[45] Bixler G D, Bhushan B. Rice- and butterfly-wing effect inspired self-cleaning and low drag micro/nanopatterned surfaces in water, oil, and air flow. Nanoscale, 2014, 6, 76-96.

[46] Vasudevan R, Kennedy A J, Merritt M, Crocker F H, Baney R H. Microscale patterned surfaces reduce bacterial fouling-microscopic and theoretical analysis. Colloids and Surface B: Biointerfaces, 2014, 117, 225-232.

[47] Hasan J, Chatterjee K. Recent advances in engineering topography mediated antibacterial surfaces. Nanoscale, 2015, 7, 15568-15575.

[48] Ercan B, Taylor E, Alpaslan E J, Webster T. Diameter of titanium nanotubes influences anti-bacterial efficacy. $\mathrm{Na}$ notechnology, 2011, 22, 295102. 